\section{JURNAL ABDIMAS

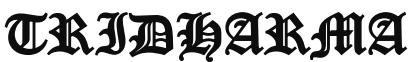 AtA}

P-ISSN 2715-7105, E-ISSN 2716-070X

Jurnal ABDIMAS Vol. 2, No. 1, Januari 2021,Hal (79-89)

@Prodi Manajemen Fakultas Ekonomi Universitas Pamulang

Email: abdimasjurnal.unpam@gmail.com Telp: (021) 741-2566

\title{
MENUMBUHKAN WIRAUSAHA KECIL MENENGAH YANG TANGGUH DI PONDOK PESANTREN AL HANIF, KEL. SERUA, KEC. CIPUTAT, KOTA TANGERANG SELATAN
}

\author{
Surti Wardani, Arif Siaha Widodo, Hanum Puspa Dhiani, \\ Mutmainnah, Nugroho Adi Utomo
}

\section{Dosen Fakultas Ekonomi Universitas Pamulang}

Email: dosen01707@ unpam.ac.id, dosen01725@ unpam.ac.id, dosen01734@unpam.ac.id, dosen01720@unpam.ac.id, dosen0162@unpam.ac.id

\begin{abstract}
ABSTRAK
Usaha Mikro Kecil dan Mengenaha (UMKM) merupakan aktivitas yang erat dengan kehidupan keseharian saat ini, terutama di era serba digital. Sebagian besar pelaku UMKM telah mengalihkan kehadiran toko secara fisik dengan menggunakan $e$-commerce atau secara daring (online). Urgensi UMKM bagi Negara RI saat ini sangat penting dirasakan, sejalan dengan data kementrian Koperasi dan UKM RI tentang data jumlah unit UKM yang memiliki pangsa pasar sekitar 99,99\% (62,9 juta unit) dari total keseluruhan pelaku usaha di Indonesia pada tahun 2017. Dengan modal yang relatif terjangkau. Memudahkan menjadi pelaku UMKM atau berwirausaha, termasuk di pondok pesantren. Pergeseran fungsi awal pesantren yang semula murni sebagai sebagai pusat pendidikam agama, kini juga sebagai penggerak roda ekonomi masyarakat sekitarnya. Pondok pesantren yang berwawasan kewirausahaan membuat eksistensi pesantren menguat dan mampu memberikan alternatif solusi atas persoalan sosial yang terjadi masyarakat. Sehingga mampu memberikan pembekalan kepada para santri untuk memulai usahanya sendiri dan juga dapat membantu menyejahterakan masyarakat sekitar dengan cara membuka lapangan pekerjaan dari usaha tersebut, khususnya di tangah pandemi covid 19. Dukungan pemerintah dalam bentuk langkah-langkah kebijakan guna mempertahankan dan mengembangkan kegiatan wirausaha yang tangguh dalam kondisi krisis ini sangat dibutuhkan. Upaya menumbuhkan jiwa wirausaha melalui pembinaan sikap seseorang yang mengarah kepada karakteristik perilaku wirausaha, dalam hal ini termasuk wirausaha santri melalui kondisi pembelajaran yang kondusif. Di antaranya adalah pembelajaran bersifat penyadaran, pemberdayaan, dan pemandirian. Kesemuanya guna memotivasi santri dalam meningkatkan dan mengembangkan pengetahuan, ketrampilan, serta keahliannya. Sejalan dengan hal di atas, maka tim dosen Prodi Manajemen S1 Universitas Pamulang telah melakukan kegiatan PKM di Pondok Pesantren Yatim Alhanif Kel. Serua Kec. Ciputat Kota Tangerang Selatan. Kegiatan PKM dilaksanakan selama 3 hari pada tanggal 5-7 Nopember 2020 dengan tema Menumbuhkan Wirausaha Kecil Menengah Yang Tangguh di Pondok Pesantren Yatim Al Hanif Kel. Serua Kec. Ciputat Kota Tangerang Selatan. Bentuk kegiatan PKM yang telah dilaksanakan berupa seminar dan forum diskusi terbuka dengan peserta para santriwan/wati Pondok Pesantren Yatim Alhanif, terutama yang terlibat dalam pengelolaan usaha Kafe Teras Santri.
\end{abstract}

Kata Kunci: Wirausaha,UMKM, Tangguh, Pondok Pesantren 


\section{JURNAL ABDIMAS

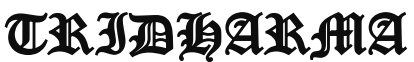

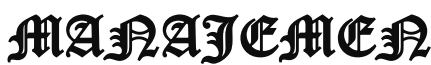

P-ISSN 2715-7105, E-ISSN 2716-070X

Jurnal ABDIMAS Vol. 2, No. 1, Januari 2021,Hal (79-89)

@Prodi Manajemen Fakultas Ekonomi Universitas Pamulang

Email: abdimasjurnal.unpam@gmail.com Telp: (021) 741-2566

\begin{abstract}
Micro, Small and Medium Enterprises (UMKM) are activities that are closely related to daily life today, especially in digital era. Most of the UMKM players have shifted their physical store presence by using e-commerce or online. The urgency of UMKMs for the Republic of Indonesia were played a high role, in line with data from the Indonesian Ministry of Cooperatives and SMEs, data mentioned on the number of SME units that have a market share of around 99.99\% (62.9 million units) of the total business actors in Indonesia in 2017. With relatively affordable capital. Make it easy to become a UMKM or entrepreneurial actor, including in boarding schools.

The shift in the initial function of the pesantren, which was originally purely a center for religious education, is now also a driving force for the economy of the surrounding community. Islamic boarding schools with entrepreneurial insight have strengthened the existence of the pesantren and are able to provide alternative solutions to social problems that occur in society. So that they are able to provide supplies to students to start their own businesses and can also help improve the welfare of the surrounding community by opening jobs from these businesses, especially in the midst of the Covid 19 pandemic.

Government support in the form of policy measures to maintain and develop resilient entrepreneurial activities in this crisis is urgently needed. Efforts to cultivate an entrepreneurial spirit through fostering a person's attitude that lead to the characteristics of entrepreneurial behavior, in this case, including entrepreneurship of students through conducive learning conditions. Among them are learning in the form of awareness, empowerment, and independence. All of which are intended to motivate the students in improving and developing their knowledge, skills and expertise.

In line with the above, the team of lecturers for the Undergraduate Management Program at Pamulang University has carried out PKM activities at the Alhanif Kel. Serua Kec. Ciputat, South Tangerang City. PKM activities were carried out for 3 days on 5-7 November2020 with the theme Growing Strong Small and Medium Entrepreneurs at the Alhanif Orphanage Boarding School, Kel. Serua Kec. Ciputat, South Tangerang City. The form of PKM activities were in seminars and open discussion forums. The participants were students of the Alhanif Orphanage Islamic Boarding School, especially those whom directly involved in managing the Teras Santri Cafe business.
\end{abstract}

Keywords: Entrepreneurship, UMKM, Resilient, Islamic Boarding School.

\section{PENDAHULUAN}

Pertumbuhan ekonomi merupakan
salah satu faktor penting dalam
keberlangsungan suatu negara.
Perekonomian suatu negara menjadi salah
satu indikator untuk mengukur
kesejahteraan masyarakat di negara

tersebut. Ekonomi suatu negara dapat bertumbuh dengan beberapa faktor pendukung, salah satunya adalah dari sumber daya manusianya. Sumber daya ini dapat menyumbang pertumbuhan ekonomi dengan kemampuan (skill) yang mumpuni sehingga mereka dapat membuka usahanya sendiri atau yang lebih dikenal dengan 


\section{JURNAL ABDIMAS

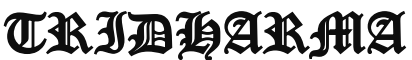 AtA}

P-ISSN 2715-7105, E-ISSN 2716-070X

Jurnal ABDIMAS Vol. 2, No. 1, Januari 2021,Hal (79-89)

@ Prodi Manajemen Fakultas Ekonomi Universitas Pamulang

Email: abdimasjurnal.unpam@ gmail.com Telp: (021) 741-2566 istilah wirausaha. Kegiatan wirausaha ini merupakan kegiatan ekonomi yang dilakukan oleh rakyat yang kemudian disebut sebagai Usaha Mikro, Kecil, dan Menengah (UMKM). Hastuti $d k k$. (2020) menjelaskan UMKM sebagai kegiatan usaha yang mampu memperluas lapangan kerja dan memberikan layanan ekonomi yang luas pada masyarakat. Peran UMKM dalam proses pemetaan dan peningkatan pendapatan masyarakat sudah tidak diragukan lagi. Selain itu UMKM dapat mendorong pertumbuhan ekonomi dan berperan dalam mewujudkan stabilitas nasional. Budiarto $d k k$. (2015) menambahkan UMKM juga mampu bertahan di tengah krisis karena sektor usaha kecil tidak terlalu tergantung

pada bahan baku impor dalam proses produksinya dan sumber dana usaha kecil umumnya berasal dari dalam negeri sehingga tidak terlalu terpengaruh akan depresiasi rupiah.

Karakteristik yang dimiliki oleh pelaku UMKM membuat pertumbuhan UMKM di Indoensia semakin berkembang. Karakteristik tersebut antara lain:

a. Fleksibel, yaitu apabila menghadapi hambatan dalam kegiatan usahanya akan mudah berpindah ke usaha lain;

b. Dari segi permodalan tidak terlalu bergantung pada modal dari luar, tetapi dia dapat berkembang dengan kekuatan modal sendiri;

c. Dalam hal pinjaman, terutama pengusaha kecil sektor tertentu seperti pedagang, sanggup mengembalikan pinjaman dengan bunga yang cukup tinggi;

d. UMKM tersebar di seluruh Indonesia dengan kegiatan usaha di berbagai sektor, merupakan sarana dan distributor barang dan jasa dalam melayani kebutuhan masyarakat (Prawirokusumo, 1999 dalam Budiarto $d k k$. 2015).

Kewirausahaan dapat dibina dan ditumbuhkembangkan sebagai suatu karakter yang potensial sehingga mampu memperkuat perekonomian secara mikro maupun makro suatu daerah. Menurut Putra (2012, dalam Handika dan Azhara, 2019), minat berwirausaha dipengaruhi oleh beberapa faktor, seperti faktor lingkungan, harga diri, peluang, kepribadian, visi, dan pendapatan. Minat berwirausaha berdasarkan Alimudin (2015, dalam Handika dan Azhara, 2019) dapat ditingkatkan melalui proses pembelajaran atau dengan kata lain memberikan wawasan akan kewirausahaan. Hadiyati (2011, dalam Handika dan Azhara, 2019) menambahkan bahwa kewirausahaan akan meningkat jika inovasi juga meningkat.

Dewasa ini semakin banyak generasi muda yang memulai usahanya sendiri dengan berwirausaha. Tidak terkecuali para santri yang berada di dalam pondok pesantren. Definisi dari pondok pesantren itu sendiri adalah lembaga pendidikan tradisional Islam untuk mempelajari, memahami, mendalami, menghayati, dan mengamalkan ajaran Islam dengan menekankan pentingnya moral keagamaan sebagai pedoman seharihari (Rofiq, 2005 dalam Maksum, 2020). Pesantren pada masa kini memiliki fungsi tidak hanya sebagai pusat pembelajaran ilmu agama namun juga memiliki peran dalam menghidupkan perekonomian masyarakat sekitar pesantren. Fokus dari pesantren tidak hanya di pendidikan agama (tafaqquh fidin) saja namun juga berfokus pada pengembangan ekonomi (tafaqquh fitijarah). Para santri diharapkan tidak hanya memahami ilmu agama namun juga dapat memulai usahanya sendiri melalui kegiatan wirausaha (Setiawan, 2019). Hal 


\section{JURNAL ABDIMAS

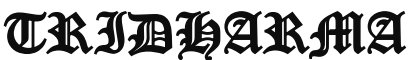 AtA}

P-ISSN 2715-7105, E-ISSN 2716-070X

Jurnal ABDIMAS Vol. 2, No. 1, Januari 2021,Hal (79-89)

@Prodi Manajemen Fakultas Ekonomi Universitas Pamulang

Email: abdimasjurnal.unpam@gmail.com Telp: (021) 741-2566 ini dapat dilihat dari banyaknya pesantren yang membuka usaha seperti koperasi, rumah makan, ataupun bentuk usaha lain.

Saat ini dunia masih berada dalam situasi krisis virus corona. Pandemi covid 19 tersebut telah membawa dampak luas di berbagai aspek, tak terkecuali bagi negara Indonesia. Dirjen Pajak Kementerian Keuangan RI, yang dikutip dari Republika.co.id (2020) menyebutkan tiga dampak dari adanya COVID-19 terhadap perekonomian Indonesia. Dampak pertama yaitu membuat konsumsi rumah tangga atau daya beli yang merupakan penopang $60 \%$ ekonomi Indonesia jatuh. Hal ini dibuktikan dengan data BPS yang mencatat penurunan konsumsi dari 5,02\% pada Q1 2019 ke 2,84\% pada Q1 2020.

$\begin{array}{rrr}\text { Dampak } & \text { kedua adalah pandemi } \\ \text { COVID-19 } & \text { ini } & \text { menimbulkan }\end{array}$ ketidakpastian yang berkepanjangan sehingga investasi menjadi lemah dan berimplikasi pada terhentinya usaha. Dampak ketiga, seluruh dunia mengalami pelemahan ekonomi sehingga harga komoditas turun dan ekspor Indonesia ke beberapa negara menjadi terhenti (Republika.co.id 2020). Adanya pandemi ini tentu memengaruhi produktivitas para wirausahawan terutama yang berskala UMKM. Oleh karena itu Pemerintah mengambil beberapa kebijakan dalam memulihkan kondisi ekonomi negara. Dilansir dari Kompas.com (2020), terdapat lima langkah yang dilakukan oleh Pemerintah. Pertama, Pemerintah melakukan belanja besar-besaran untuk meredam kontraksi ekonomi akibat COVID-19. Kedua, Pemerintah membentuk Komite Penanganan COVID19 dan Pemulihan Ekonomi Nasional. Ketiga, Pemerintah memberi bantuan kredit berbunga rendah serta menyiapkan berbagai program agar UMKM dapat produktif kembali. Keempat, Pemerintah menempatkan dana di perbankan guna memutar roda ekonomi. Terakhir, Pemerintah melakukan penjaminan kredit modal kerja untuk korporasi. Dari langkahlangkah tersebut, pada langkah ketiga yang menyatakan bahwa Pemerinta memberikan bantuan kredit berbunga rendah pada UMKM memberikan harapan kepada para pelaku UMKM untuk dapat meneruskan usahanya di tengah pandemi. Setidaknya, usaha mereka masih memiliki harapan dengan adanya kebijakan dari Pemerintah. Selain itu, di era digital seperti sekarang ini makin memudahkan para wirausahawan untuk memasarkan produknya lebih luas dan real time melalui platform e-commerce maupun pemasangan iklan di media sosial ataupun website.

Pondok Pesantren Yatim Alhanif telah memiliki sebuah unit wirausaha dengan nama Teras Santri Alhanif, yaitu sebuah kafe yang menawarkan makanan Timur Tengah serta cemilan dan minuman kekinian. Kafe ini baru berusia sebulan dan belum memiliki banyak pelanggan, apalagi di tengah pandemi seperti ini. Kegiatan operasional kafe sepenuhnya dilakukan oleh pengurus pesantren beserta para santri Pondok Pesantren Yatim Alhanif. Namun demikian, para pengurus dan santri masih awam dalam menjalankan usaha serta bagaimana mengelola sebuah kafe. Permasalahan ini kemudian yang kami angkat sebagai tema Pengabdian Kepada Masyarakat (PKM) kali ini. Pengabdian Kepada Masyarakat ini merupakan salah satu kewajiban seorang dosen dalam melaksanakan Tri Dharma Perguruan Tinggi. Oleh karena itu, pada kesempatan kali ini kami dari tim dosen Manajemen Universitas Pamulang mengangkat tema "Menumbuhkan Wirausaha Kecil Menengah Yang Tangguh di Pondok 


\section{JURNAL ABDIMAS

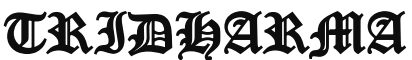 AtA 12 ATU}

P-ISSN 2715-7105, E-ISSN 2716-070X

Jurnal ABDIMAS Vol. 2, No. 1, Januari 2021,Hal (79-89)

@ Prodi Manajemen Fakultas Ekonomi Universitas Pamulang

Email: abdimasjurnal.unpam@gmail.com Telp: (021) 741-2566

\section{Pesantren Yatim Al Hanif Kel. Serua Kec. Ciputat Kota Tangerang Selatan."}

\section{RUMUSAN MASALAH}

Memperhatikan permasalahan yang ada pada pengelolaan wirausaha kafe oleh santriwan dan satriwati di Pondok Pesantren Yatim Al Hanif, maka rumusan masalahnya yaitu:

1. Bagaimana santriwan dan santriwati Pondok Pesantren Yatim Al Hanif dapat termotivasi untuk menjadi wirausahawan yang mandiri, tangguh dan inovatif?

2. Bagaimana santriwan dan santriwati Pondok Pesantren Yatim Al Hanif dapat mengelola Kafe Teras Santri Al Hanif dengan baik?

3. Bagaimana santriwan dan santriwati Pondok Pesantren Yatim Al Hanif tergerak dan mampu menerapkan strategi pemasaran yang tepat sasaran dengan menggunakan kemajuan teknologi digital dalam mengelola Kafe Teras Santri Al Hanif di era digital ?

\section{TINJAUAN PUSTAKA}

Menurut Kamus Besar Bahasa Indonesia (KBBI) online, pengertian wirausaha sama dengan wiraswasta, yaitu orang yang pandai atau berbakat mengenali produk baru, menentukan cara produksi baru, menyusun operasi untuk pengadaan produk baru, memasarkannya, serta mengatur permodalan operasinya.

Menurut Thomas W. Zimmerer dan Norman M. Scarbrough Wirausahawan adalah orang yang menciptakan bisnis baru dengan mengambil resiko dan ketidakpastian demi mencapai keuntungan dan pertumbuhan dengan cara mengidentifikasi peluang dan menggabungkan sumber daya yang diperlukan untuk mendirikannya (Fahmi; 2014: 20)

Wirausaha juga diartikan sebagai orang yang mendirikan, mengelola, mengembangkan dan melembagakan perusahaan miliknya atau kemampuan yang dimiliki oleh seseorang untuk melihat dan menilai kesempatan-kesempatan bisnis, mengumpulkan sumber dayasumber daya yang dibutuhkan untuk mengambil tindakan yang tepat dan mengmbil keuntungn dalam rangka meraih sukses (Gitosardjono; 2013: 204).

\section{Kewirausahaan}

Pengertian kewirausahaan berdasarkan Keputusan Mentri Koperasi dan Pembinaan Pengusaha Kecil Nomor: 961/KEP/M/XI/1995: Kewirausahaan merupakan rangkaian dari sikap, perilaku dan kemampuan serta semangat, individu untuk mengatur sebuah kegiatan yang bertujuan pada usaha menciptakan, menemukan dan menetapkan mekanisme kerja teknologi ataupun produk yang belum ada sebelumnya.

Entrepreneurship (Kewirausahaan) menurut Instruksi Presiden Republik Indonesia (INPRES) No. 4 Tahun 1995 tentang Gerakan Nasional Memasyarakatkan dan membudayakan Entrepreneur adalah semangat, sikap, perilaku dan kemampuan seseorang dalam menangani usaha dan atau kegiatan yang mengarah pada upaya mencari menciptakan, menerapkan cara kerja, teknologi dan produk baru dengan meningkatkan efisiensi dalam rangka memberikan pelayanan yang lebih baik dan atau memperoleh keuntungan yang lebih besar (Winarno; 2011: 20).

Kewirausahaan adalah suatu ilmu yang mengkaji tentang pengembangan dan pembangunan semangat kreatifitas serta 


\section{JURNAL ABDIMAS

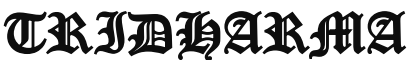 AtA 12 ATU}

P-ISSN 2715-7105, E-ISSN 2716-070X

Jurnal ABDIMAS Vol. 2, No. 1, Januari 2021,Hal (79-89)

@Prodi Manajemen Fakultas Ekonomi Universitas Pamulang

Email: abdimasjurnal.unpam@gmail.com Telp: (021) 741-2566 berani menanggung risiko terhadap pekerjaan yang dilakukan demi mewujudkan hasil karya tersebut (Fahmi; 2014: 2).

Peter F. Drucker menjelaskan kosep kewirausahaan merujuk pada sifat, watak, dan ciri-ciri yang melekat pada seseorang yang mempunyai kemauan keras untuk mewujudkan gagasan inovatif ke dalam dunia usaha yang nyata dan dapat mengembangkannya dengan tangguh (Suryana; 2014: 10).

\section{Usaha Mikro Kecil dan Menengah (UMKM)}

Pemerintah telah mengatur tersendiri perihal UMKM di Negara Kesatuan RI, serta menetapkan definisi UMKM dalam Undang-Undang Republik Indonesia No.20 Tahun 2008 tentang UMKM (Tulus; 2009: 16). (1Tulus T.H. Tambunan, UMKM di Indonesia, (Bogor : Ghalia Indonesia, 2009), hal.16)Dalam Pasal 1 dari UU terebut, dinyatakan bahwa Usaha mikro adalah usaha produktif milik orang perorangan dan/atau badan usaha perorangan yang memiliki kriteria usaha mikro sebagaimana diatur dalam UU tersebut.(Hal 17) Usaha kecil adalah usaha ekonomi produktif yang berdiri sendiri, yang dilakukan oleh orang perorangan atau badan usaha yang buka merupakan anak perusahan atau bukan anak cabang yang dimiliki, dikuasai atau menjadi bagian, baik langsung maupun tidak langsung, dari usaha menengah atau usaha besar yang memenuhi kriteria usaha kecil sebagaimana dimaksud dalam UU tersebut (Tambunan; 2009: 18).

\section{METODE PELAKSANAAN}

Dalam pelaksanaan kegiatan ini metode yang kita ambil adalah dengan melibatkan banyak pihak selain dari pihak santriwan dan santriwati juga melibatkan pihak pengurus serta ustadz dan ustadzah Pondok Pesantren Al Hanif. Dalam proses kegiatan kali ini metodenya berupa seminar dimana narasumber akan berinteraksi aktif dengan audience, jadi lebih bersifat sharing interaktif, agar semua yang terlibat bisa merasakan manfaatnya langsung dan mendapatkan wawasan yang lebih mendalam tentang bagaimana mengelola usaha yang baik, sehingga pada akhirnya nanti dapat menerapkan dalam kegiatan usaha di Pondok Pesantren maupun setelah lulus nantinya.

\section{HASIL DAN PEMBAHASAN}

Sebelum pelaksanaan acara Pengabdian Kepada Masyarakat oleh tim dosen Fakultas Ekonomi, Program Studi Manajemen, Universitas Pamulang di Pondok Pesantren Yatim A 1Hanif, Kota Tangerang Selatan, dilakukan, tim dosen yang terlibat telah melakukan beberapa rangkaian agenda kegiatan. Kegiatan diawali dengan dilakukannya rapat pembentukan susunan panitia pada hari Jumat tanggal 2 Oktober 2020. Kemudian setelah terbentuk susunan panitia, dilakukan penyusunan proposal kegiatan lalu diajukan pada hari Sabtu tanggal 24 Oktober 2020 dan mendapat persetujuan dari Lembaga Penelitian dan Pengabdian Kepada Masyarakat Universitas Pamulang (LPPM UNPAM).

Dengan disetujuinya proposal tersebut, kami menyampaikan kepada Rektor Universitas Pamulang untuk menindaklanjuti acara tersebut sampai menunggu waktu pelaksanaan yang ditentukan oleh pihak Pondok Pesantren Yatim Al Hanif Kota Tangerang Selatan. Setelah melakukan beberapa kali koordinasi dengan pihak Pondok Pesantren Yatim AlHanif Kota Tangerang Selatan yang dituju pada akhirnya disepakati bersama acara dilaksanakan pada hari 


\section{JURNAL ABDIMAS

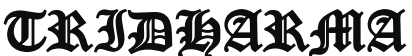 AtA 12 ATU}

Kamis-Sabtu, 5-7 Nopember 2020.

\section{Rincian Acara Pelaksanaan Kegiatan}

Rincian pelaksanaan kegiatan pengabdian kepada masyarakat di Pondok Pesantren Yatim AlHanif adalah sebagai berikut:

\section{Briefing}

Pelaksanaan PKM dilaksanakan di Pondok Pesantren Yatim Al Hanif, Kota Tangerang Selatan. Sebelum acara dimulai tim dosen PKM melakukan briefing dan temu sapa dengan Pimpinan Pondok Pesantren Yatim Al Hanif, Kota Tangerang Selatan, serta mempersiapkan segala sesuatu yang dibutuhkan untuk menunjang kegiatan seminar, pada hari pertama Kamis, 5 Nopember 2020.

\section{Registrasi Peserta}

Pada hari kedua, Jum'at 6 Nopember 2020, acara dimulai dengan registrasi peserta seminar pada pukul 09.00 WIB, sambil memastikan penggunaan masker oleh setiap peserta dan panitia. Setelah itu peserta menempati kursi yang sudah disediakan dan diatur jaraknya berdasarkan aturan pemerintah tentang protokol kesehatan PSBB. Jumlah peserta yang hadir sebanyak 50 peserta, yang terdiri dari santriwan dan santriwati Pondok Pesantren Yatim AlHanif Kota Tangerang Selatan.

\section{Pembukaan Acara}

Pembukaan acara oleh MC dimulai pada pukul 09.15 WIB kemudian dilakukan pembacaan doa pembukaan, setelah itu bersama-sama menyanyikan lagu Indonesia Raya dilanjutkan dengan pembacaan ayat suci Alqur'an dan doa.

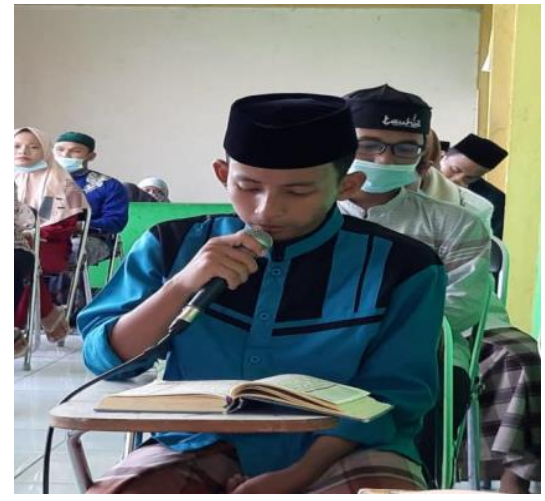

Gambar 1.1. Pembacaan Al-Quran

\section{Sambutan}

Kegiatan dimulai pukul 09.20 WIB. Sambutan pertama disampaikan oleh Ketua tim PKM dosen Manajemen UNPAM, Surti Wardani S.Sos., M.Si, yang menjelaskan peran dosen terkait Tri Dharma Perguruan Tinggi yang salah satunya melakukan Pengabdian Kepada Masyarakat. Sambutan terakhir dari Pimpinan Pondok Pesantren Yatim Al Hanif, Kota Tangerang Selatan yang di sampaikan oleh K.H. Ahmad Jazuli.

\section{Pembahasan Materi dan Diskusi}

Pelaksanaan pemaparan materi berupa seminar yang disampaikan oleh pemateri atau narasumber. Pemaparan materi disampaikan oleh Arif Siaha Widodo, S.E., M.M., terkait Kewirausahaan dan Strategi Pemasaran. Kegiatan diakhiri dengan diskusi dari peserta yang mempertanyakan permasalahan-permasalahan riil. Pembahasan materi dan diskusi dilaksanakan di Ruang terbuka, lantai empat, Pondok Pesantren Yatim Al Hanif, Kota Tangerang Selatan, pada pukul 09.30 - 11.00 WIB, untuk persiapan sholat Jum'at. . 


\section{JURNAL ABDIMAS P-ISSN 2715-7105, E-ISSN 2716-070X

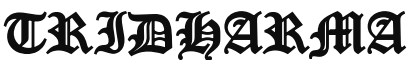 Jurnal ABDIMAS Vol. 2, No. 1, Januari 2021,Hal (79-89) AlA

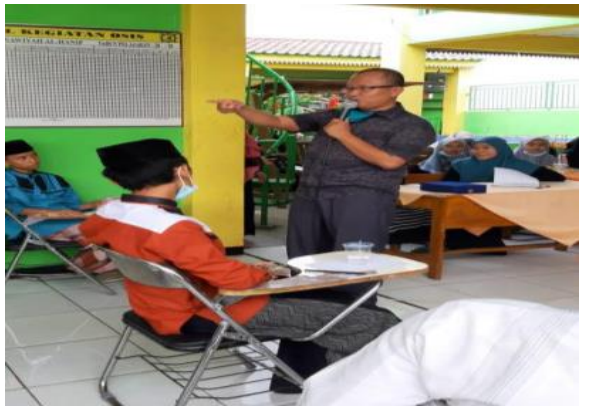

Gambar 1.2. Pembahasan Materi dan Diskusi

\section{Penutupan, Serah Terima Plakat dan Doa Penutup}

Setelah acara diskusi selesai dilanjutkan dengan pembacaan doa penutup, dan pemberian plakat dari tim dosen kepada pihak Pondok Pesantren Yatim Al Hanif Kota Tangerang Selatan, serta sesi foto bersama. Acara ditutup oleh MC yang menyatakan berakhirnya seminar ini tepat pada pukul 11.30 WIB. Alhamdulillah, kegiatan PKM berjalan dengan lancar.

\section{KESIMPULAN DAN SARAN Kesimpulan}

Berdasarkan pelaksanaan kegiatan PKM yang telah dilaksanakan di Pondok Pesantren Yatim Al Hanif, Jl. Bukit Indah No.5, RT.03/RW02, Serua, Kec. Ciputat, Kota Tangerang Selatan, Banten 15414, pada hari Rabu-Jumat, 5-7 Nopember 2020, dapat ditarik kesimpulan bahwa secara umum kegiatan PKM dapat terlaksana dengan baik dan kondusif walau di tengah pandemi covid 19. Kegiatan PKM ini mendapat sambutan dan dukungan positif dan dari pihak Pondok Pesantren Yatim Al Hanif, dari segi tempat, sarana prasarana dan akomodasi, serta antusiasme para peserta yaitu santriwan dan santriwati. Dengan demikian tercipta sinergi yang positif antara Pondok Pesantren Yatim AlHanif dengan Universitas Pamulang, khususnya oleh dosen Tim PKM dengan peserta.

\section{Saran}

Berdasarkan kegiatan yang telah dilaksanakan berikut beberapa saran yang dapat kami sampaikan untuk kemajuan Pondok Pesantren Yatim Al Hanif, yaitu:

1. Diperlukan peningkatan motivasi dan semangat berwirausaha bagi santriwan/wati secara kontinu baik dari pihak internal maupun eksternal Pondok Pesantren AlHanif.

2. Masih perlunya pengembangan penerapan strategi pemasaran secara digital bagi Kafe Teras Santri, yang disesuaikan dengan situasi dan kondisi Pondok Pesantren Yatim Al Hanif.

3. Santriwan/wati perlu mengasah dan peningkatan kreativitas dan inovasi serta selalu mengamati kondisi lingkungan sekitar, sehingga UMKM Pondok Pesantren Yatim AlHanif mampu berperan serta pada proses pembangunan daerah yaitu sebagai generator pembangunan lingkungan, pribadi, distribusi, pemeliharaan lingkungan, dan kesejahteraan, serta bisa menjadi contoh bagi anggota masyarakat sebagai generasi santri unggul yang patut diteladani.

\section{DAFTAR PUSTAKA}

Bisnis.com. 2020. Dampak Nyata Pandemi Corona Terhadap Wirausaha. 23 Juni 2020.

https://entrepreneur.bisnis.com/rea $\mathrm{d} / 20200623 / 52 / 1256598 /$ dampaknyata-pandemi-corona-terhadapwirausaha. Diakses pada tanggal 16 Oktober 2020 pk. 12.57 WIB. 


\section{JURNAL ABDIMAS

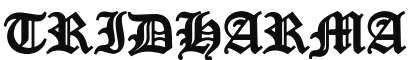

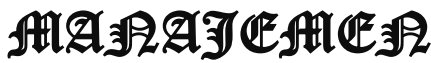

P-ISSN 2715-7105, E-ISSN 2716-070X

Jurnal ABDIMAS Vol. 2, No. 1, Januari 2021,Hal (79-89)

@ Prodi Manajemen Fakultas Ekonomi Universitas Pamulang

Email: abdimasjurnal.unpam@gmail.com Telp: (021) 741-2566
Bisnismuda.id. 2020. Mengembangkan Wirausaha di Tengah Pandemi COVID-19. Juni 2020. https://bisnismuda.id/read/67-tutyqueen/mengembangkanwirausaha-di-tengah-pandemicovid-19. Diakses pada tanggal 16 Oktober 2020 pk. 13.34 WIB.

Budiarto, $d k k$. 2015. Pengembangan UMKM Antara Konseptual dan Pengalaman Praktis. Cetakan Pertama. Gadjah Mada University Press: Yogyakarta.

Dhiani, H.P.; Widodo, A.S.; Hanum, N.; Mutmainnah, M.; Dimyati, A. 2020. Membangun Motivasi Siswa yang Mampu Memanajemen Waktu dengan Baik. Jurnal PKM Abdi Laksana 1(2).

Handika, F.S. dan S.U. Azhara. 2019. Membangun Ekonomi Masyarakat Melalui Edukasi dan Pelatihan Wirausaha Kreatif. PKN STAN Press. Jurnal Kuat: Keuangan dan Akuntansi Terapan 1(2): 83-88 hal.

Hastuti, P., dkk. 2020. Kewirausahaan dan UMKM. Cetakan Pertama. Yayasan Kita Menulis: Medan.

Fahmi, Irham. 2014. Kewirausahaan Toeri, Kasus dan Solusi, Bandung: Alfabeta.

Gitosardjono, Sukamdani S. 2013. Wirausaha Berbasis Islam \& Kebudayaan, Jakarta: Pustaka Bisnis Indonesia.

Kompas.com. 2020. 5 Langkah Upaya Pemerintah Kembalikan Pertumbuhan Perekonomian Nasional. 7 Agustus 2020. https://nasional.kompas.com/read/ 2020/08/07/16224171/5-upayapemerintah-kembalikanpertumbuhan-perekonomiannasional?page $=$ all. Diakses pada 16 Oktober 2020 pk. 16.10 WIB.

Maksum, A. 2020. Keefektifan Penerapan Kurikulum Terpadu Pada Pondok Pesantren Modern. Cetakan Pertama. CV. Syntax Corporation Indonesia: Cirebon.

Mutmainnah, M.; Dhiani, H. P. 2020. Kisah Nabi Sebagai Peningkatan Motivasi Dalam Kegiatan Santriwan/Wati Ditaman Pendidikan Alqur'an Miftahul Huda. Jurnal ABDIMAS, 1(1).

Mutmainnah, M.; Widodo, A.S.; Dimyati, A.; Dhiani, H.P.; Wardani, S. 2020. Aplikasi Social Responsibility: Kegiatan Bakti Sosial Dalam Masa Pandemi Covid-19 Di Kelurahan Kukusan RT 06 RW 05 Kecamatan Beji Kota Depok Jawa Barat 16425. Jurnal Dedikasi PKM 1(3).

Pasaribu, V. L. D., Susanti, F., \& Hartuti, E. T. K. (2019). Memotivasi Siswa dan Siswi SMK Letris Indonesia di Dalam Menentukan Pilihan Untuk Melanjutkan Pendidikan Atau Bekerja Setelah Lulus Sekolah. Jurnal Pengabdian Dharma Laksana, 1(2), 161-172.

Pasaribu, V. L. D., Agrasadya, A., Shabrina, N., \& Krisnaldy, K. (2020). MENJADI ENTERPRENEUR MUDA YANG MEMILIKI JIWA LEADERSHIP UNTUK MENGHADAPI MASA DEPAN. Abdi Laksana, 1(1).

Pasaribu, V. L. D., Elburdah, R. P., Sudarso, E., \& Fauziah, G. (2020). PENGGUNAAN MANAJEMEN WAKTU TERHADAP PENINGKATAN 


\section{JURNAL ABDIMAS

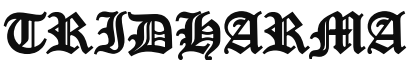 AIA}

P-ISSN 2715-7105, E-ISSN 2716-070X

Jurnal ABDIMAS Vol. 2, No. 1, Januari 2021,Hal (79-89)

@ Prodi Manajemen Fakultas Ekonomi Universitas Pamulang

Email: abdimasjurnal.unpam@ gmail.com Telp: (021) 741-2566
PRESTASI BELAJAR DI SMP ARAISIYAH. Jurnal ABDIMAS Tri Dharma Manajemen, 1(1).

Pasaribu, V. L. D., Sulaiman, S., Sutiman, S., Thaharudin, T., \& Purnomo, B. Y. (2020). PENGENALAN LETAK POSYANDU TERDEKAT DIKELURAHAN PISANGAN DENGAN MANAJEMEN PEMASARAN REVOLUSI $\quad 4.0 \quad$ UNTUK MENINGKATKAN PENGETAHUAN MASYARAKAT LETAK DAN FUNGSI POSYANDU TERDEKAT PADA KELURAHAN PISANGAN. DEDIKASI PKM, 1(1), 105-110.

Pasaribu, V. L. D., Oktrima, B., Prabowo, B., Arianto, N., \& Haryoko, U. B. (2020). PROGAM PENDAMPINGAN DAN PENYELENGGARAAN PENDIDIKAN ANAK PADA USIA DINI TERHADAP PRESTASI BELAJAR DILINGKUNGAN RT 020 RW 009. KEL GIRI PENI. KEC WATES. YOGYAKARTA. JURNAL LOKABMAS KREATIF, 1(1), 71-75.

Pakpahan, A. K. 2020. COVID-19 dan Implikasi Bagi Usaha Mikro, Kecil, dan Menengah. Jurnal Ilmiah Hubungan Internasional. Fakultas Ilmu Sosial dan Politik Universitas Katolik Parahyangan. http://journal.unpar.ac.id/index.ph $\mathrm{p} /$ JurnalIlmiahHubunganInternasi ona/article/view/3870. Diakses pada 15 Oktober 2020 pk. 14.00 WIB.

Republika.co.id. 2020. Tiga Dampak Besar Pandemi Covid-19 Bagi Ekonomi RI. $15 \quad$ Juli 2020. https://republika.co.id/berita/qdgt5 p383/tiga-dampak-besar-pandemicovid19-bagi-ekonomi-ri. Diakses pada 16 Oktober 2020 pk. 14.25 WIB

Sari, A.M. Suratmin U., dan A.S. Redjeki. 2014. Peningkatan Motivasi Berwiraswasta Santri Pondok Pesantren Melalui Pelatihan Kewirausahaan. Jurusan Teknik Kimia Fakultas Teknik Universitas Muhammadiyah Jakarta. Jurnal Teknologi 6(1): 47 - 53 hal.

Suryana. 2014. Kewirausahaan Kiat dan Proses Menuju Sukses, Jakarta: Salemba Empat.

Setiawan, H. C. B. 2019. Kontribusi Praktik Kewirausahaan Di Pondok Pesantren Entrepreneur Mukmin Mandiri Waru, Sidoarjo. Program Studi Kewirausahaan Fakultas Ekonomi dan Bisnis Uni

Tambunan, Tulus T.H. 2009. UMKM di Indonesia. Bogor, Ghalia Indonesia.

Tambunan, Tulus T.H. 2012. Usaha Mikro Kecil dan Menengah di Indonesia: Isu-Isu Penting, Jakarta: LP3ES.

Setiawan, H. C. B. 2019. Kontribusi Praktik Kewirausahaan Di Pondok Pesantren Entrepreneur Mukmin Mandiri Waru, Sidoarjo. Program Studi Kewirausahaan Fakultas Ekonomi dan Bisnis Universitas Muhammadiyah Gresik. Jurnal Riset Entrepreneurship 2(2): 8-18 hal.

Ukmindonesia.id. 2019. Potret UMKM di Indonesia: Si Kecil yang Berperan Besar. 29 Juli 2019. https://www.ukmindonesia.id/bac a-artikel/62. Diakses pada 15 Oktober 2020 pk. 13.00 WIB. 
JURNAL ABDIMAS P-ISSN 2715-7105, E-ISSN 2716-070X

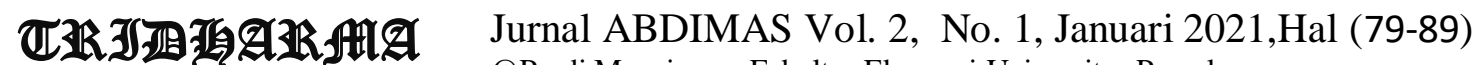

@Prodi Manajemen Fakultas Ekonomi Universitas Pamulang

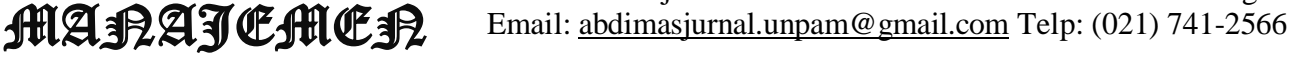

Widodo, A. S., Kumara, D., \& Wardani, S. (2020). REORIENTASI PERAN KARANG TARUNA: MENGEMBANGKAN MANAJEMEN ORGANISASI YANG SELARAS DENGAN KONTEKS PEMBANGUNAN DAERAH. Jurnal ABDIMAS Tri Dharma Manajemen, 1(1).

Winarno. 2011. Pengembangan Sikap Entreprenuership dan Intraprenuership, Jakarta: PT Indeks. 